\title{
COVID-19: Understanding the Enemy, the Battle Fought So Far, and the Battle Still to Wage!
}

\author{
Ranganadin Pajanivel ${ }^{1}$, Rajagambeeram Reeta ${ }^{2}$
}

\begin{abstract}
Together with the severe acute respiratory syndrome (SARS) coronavirus which threatened as pandemic in 2002-2003 and the MERS (Middle East respiratory syndrome) which was notified in 2012, the current and novel pathogen-novel coronavirus 2019 is the third highly pathogenic human coronavirus that has emerged in the last two decades and is exhibiting rapid survival tactics including transmissibility. Subsequent to its emergence, there has been an outpouring of information and data in the medical and nonmedical literature. The information is also so dynamic that the validity of information, especially the morbidity and mortality data become outdated everyday. This review aims at providing the overview about the agent and the epidemiological similarities and differences between the current novel coronavirus and the previous member of the family, the SARS-CoV and shared thoughts about what to be done further!

Keywords: Coronavirus, COVID-19, Novel coronavirus 2019, SARS-CoV-2.

Annals of SBV (2020): 10.5005/jp-journals-10085-8110
\end{abstract}

\section{INTRODUCTION}

Size does matter! This adage specifically suits the recent pathogen against the mankind: a novel coronavirus, which emerged in China in December, 2019, and is haunting the global nations.

Coronaviruses are RNA viruses that were discovered in the 1960s and are typically harbored in mammals and birds with potential for human disease. The classification of the different types of coronaviruses described so far is as shown in Flowchart 1.

Coronaviruses were considered trivial viruses till 2002, after the emergence of SARS-CoV, which caused pandemic in 2002-2003. ${ }^{1}$

Unlike other corona viruses that infect humans, SARS-CoV (2003-2003), MERS-CoV (2012), and the current SARS-CoV-2 are associated with severe respiratory illnesses.

The existence of the SARS-CoV-2 came into highlight with the sequencing of virus from patients affected with unexplained pneumonia outbreak in Wuhan city of China in December 2019. The disease caused by this novel corona virus (2019-nCoV) (also named as SARS-CoV-2 by WHO) has been designated as COVID-19 and has been causing huge outbreaks globally till today with mounting tolls.

\section{About Novel Coronavirus 2019}

The causative agent of the so-called COVID-19 is the new virus labeled as 2019 novel corona virus (2019-nCoV) by WHO on January 12,2020 . The disease was formally labeled as COVID-19 on February 11,2020 , by the WHO. On the same day, the coronavirus study group of the International Committee on Taxonomy of Viruses (ICTV) named 2019-nCoV as SARS-CoV-2.

SARS-CoV-2 belongs to the $ß$ Coronavirus genera of coronavirus family and is the third known zoonotic coronavirus disease after SARS and MERS. ${ }^{2}$ Although the primary and intermediate hosts of SARS and MERS are known, it has not yet been proved if a specific animal source harbors the SARS-CoV-2. It was proposed in a study by Zhu et al. that SARS-CoV-2 is a chimerical virus between a bats coronavirus and an unknown coronavirus and snakes are the most likely wildlife reservoirs. ${ }^{3}$

Subsequent study by Benvenuto et al. supported the theory that SARS-CoV-2 is transmitted from bats to humans (especially chrysanthemum headed bats). ${ }^{4}$
'Department of Pulmonary Medicine, Mahatma Gandhi Medical College and Research Institute, Sri Balaji Vidyapeeth, Puducherry, India ${ }^{2}$ Department of Biochemistry, Mahatma Gandhi Medical College and Research Institute, Sri Balaji Vidyapeeth, Puducherry, India

Corresponding Author: Ranganadin Pajanivel, Department of Pulmonary Medicine, Mahatma Gandhi Medical College and Research Institute, Sri Balaji Vidyapeeth, Puducherry, India, Phone: +91 9443493122, e-mail: pajanivelr@mgmcri.ac.in

How to cite this article: Pajanivel R, Reeta R. COVID-19: Understanding the Enemy, the Battle Fought So Far, and the Battle Still to Wage. Ann SBV 2020;9(1):7-11.

Source of support: Nil

Conflict of interest: None

SARS-CoV-2 genetic sequence has $86 \%$ homology with SARS$\mathrm{CoV}^{5}$ and high homology with bat corona viruses.

\section{Clinical-epidemiological Characteristics of COVID-19-Learning So Far}

- Elderly patients are more symptomatic and have higher fatality rates compared to younger adults. (Table 1)

- Males are proportionately higher in number than females in series reported. (Table 1)

- The transmission rate varies from $0.3 \%$ to $3.77 \%$ (average $2-3$ ). ${ }^{17}$

- The case fatality rate varies from $1.36 \%$ to $33 \%$ with the official Chinese figure around $3.17 \%$ (Different sample populations and possible viral variations could account for the range of differences across the studies.).

- Angiotensin-converting enzyme 2 (ACE2) is the identified receptor for SARS-CoV-2. ACE2 is expressed on type I and type II alveolar epithelial cells with $83 \%$ expression on type II AEC.

- Males and Asian ethnicity have a higher level of ACE2 expression that females and other ethnic groups, respectively, which probably explains the observed predominance of cases in males and non-Caucasians.

- ACE2 binding ability of SARS-CoV is $10-20$ times higher than SARS-CoV. ${ }^{18}$

() The Author(s). 2020 Open Access This article is distributed under the terms of the Creative Commons Attribution 4.0 International License (https://creativecommons. org/licenses/by-nc/4.0/), which permits unrestricted use, distribution, and non-commercial reproduction in any medium, provided you give appropriate credit to the original author(s) and the source, provide a link to the Creative Commons license, and indicate if changes were made. The Creative Commons Public Domain Dedication waiver (http://creativecommons.org/publicdomain/zero/1.0/) applies to the data made available in this article, unless otherwise stated. 
Flowchart 1: Taxonomical classification of different coronaviruses

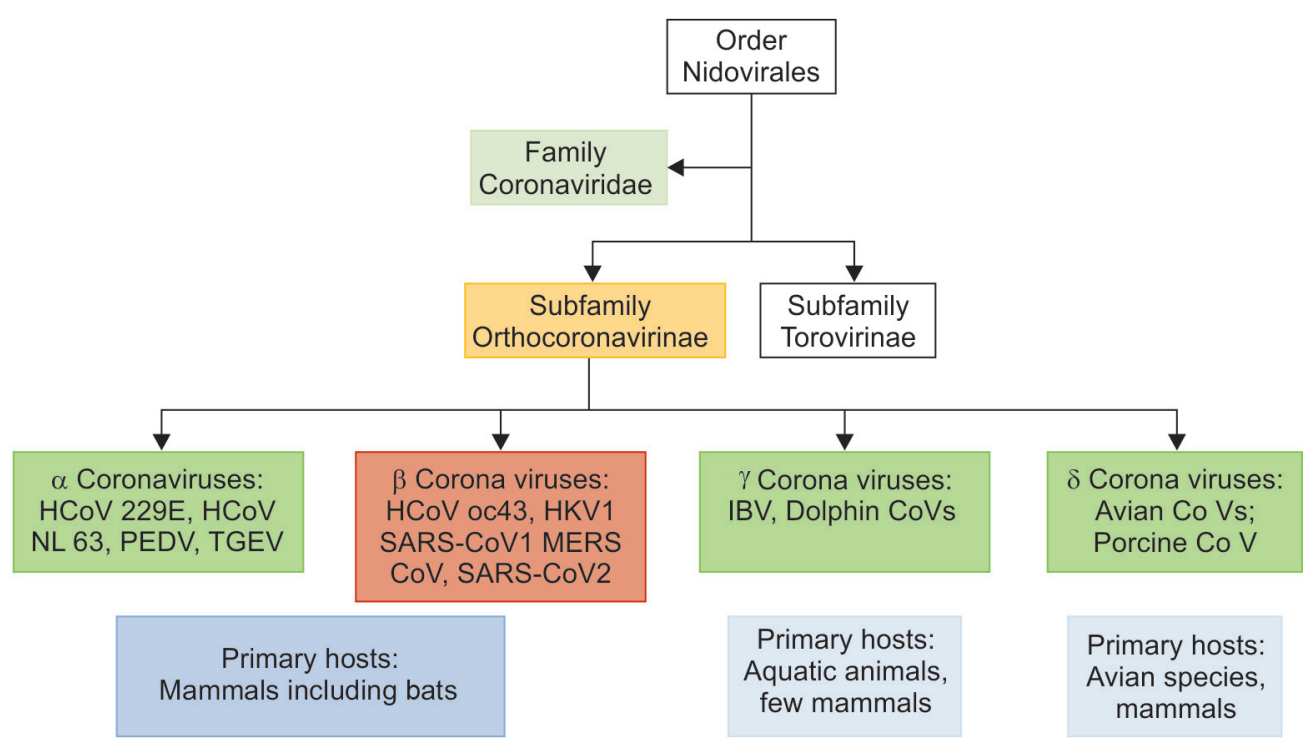

Table 1: Clinical and epidemiological studies on COVID-19

\begin{tabular}{|c|c|c|c|c|c|}
\hline Author & $n$ & Age range & Mean age & Sex (male) & Predominant clinical symptoms \\
\hline $\mathrm{WMCHHHPNCl}^{6}$ & 136 & $25-89$ & - & 66 & Fever (100\%), cough (100\%), dyspnea (100\%) \\
\hline Chaolin et al. ${ }^{7}$ & 41 & $41-58$ & 49 & 30 & $\begin{array}{l}\text { Fever 40(97.6), cough 31(75.6), dyspnea } \\
22(53.7)\end{array}$ \\
\hline Chen et al. ${ }^{8}$ & 99 & $21-82$ & 55.5 & 67 & $\begin{array}{l}\text { Fever } 82(82.8) \text {, cough } 81(81.8) \text {, hemoptysis } \\
31(31.3)\end{array}$ \\
\hline Chung et al. ${ }^{9}$ & 21 & $29-77$ & 51 & 13 & Fever $14(66.7)$, cough 9(42.9), myalgia $6(28.6)$ \\
\hline Chen et al. ${ }^{10}$ & 29 & $26-79$ & 56 & 21 & $\begin{array}{l}\text { Fever 28(96.6), cough } 21(72.4) \text {, dyspnea } \\
17(58.6)\end{array}$ \\
\hline Wang et al. ${ }^{11}$ & 138 & $42-68$ & 56 & 75 & $\begin{array}{l}\text { Fever 136(98.6), cough 82(59.4), dyspnea } \\
43(31.2) \text {, myalgia } 138(100.0)\end{array}$ \\
\hline Kui et al. ${ }^{12}$ & 137 & $20-83$ & 57 & 61 & $\begin{array}{l}\text { Fever } 112(81.8) \text {, cough 66(48.2), myalgia } \\
44(32.1)\end{array}$ \\
\hline Chang et al. ${ }^{13}$ & 13 & $34-48$ & 34 & 10 & Fever 12(92.3), cough 6(46.2), myalgia 3(23.1) \\
\hline COVID-19 team Australia ${ }^{14}$ & 15 & $8-66$ & 43 & 9 & Fever 14 (93.3), cough $11(73.3)$ \\
\hline Wang et al. ${ }^{15}$ & 34 & - & 8 & 14 & Fever $17(50.0)$, cough $13(38.2)$ \\
\hline Xiaobo et al. ${ }^{16}$ & 52 & $33.6-85.8$ & 59.7 & 35 & $\begin{array}{l}\text { Fever 51(98.1), cough 40(76.9), dyspnea } \\
33(63.5)\end{array}$ \\
\hline
\end{tabular}

WMCHHHPNCI, Wuhan Municipal Commission of Health and Health on Pneumonia of New Coronavirus Infection

\section{SARS-CoV-2 vs SARS-CoV}

The current pandemic virus, 2019-nCoV or SARS-CoV-2 is structurally related to SARS-CoV that caused 2002-2003 SARS pandemic. However, the present COVID-19 outbreak has posed critical challenges for the Public Health, Research, and Healthcare teams globally.

\section{Why COVID-19 Outbreaks is Considered a Global Threat?}

- It kills elderly with comorbid diseases as well as healthy adults. The case fatality rate as per the current situation is figured somewhere between the 1957 influenza pandemic (0.6\%) and the 1918 influenza pandemic (2\%). ${ }^{19}$

- The rate of transmission is quite efficient with an infected person spreading the disease to another 2-3 persons-an exponential of increase. Also, even mildly symptomatic or asymptomatic people can transmit the infection as the titers of virus are high in the oropharynx early in the course of the disease. ${ }^{20,21}$

This means the present COVID-19 will be much harder to contain than the past CoV pandemics.

The past coronavirus outbreak SARS (2002-2005) was successfully contained by stringent Public Health measures and top-down enforcement of community quarantine. The success of similar measures in the current situation needs an understanding of the similarities between the two viruses and more so the differences.

\section{Similarities between SARS-CoV-2 and SARS}

There are striking similarities between the two viruses (not only in name!). 
- The genome of SARS-CoV-2 has $86 \%$ similarity with SARS-CoV. ${ }^{5}$

- Bats are the probable primary hosts of origin of both SARS-CoV-2 and SARS-CoV.

- Large and densely populated human settlements in close proximity to live animal markets are the source of outbreak in both the viruses [Huang market in SARS-CoV-2 and Guangdong market in SARS-CoV].

- The primary route of transmission for both viruses is respiratory droplets.

- After droplet spread, the ACE 2 is the receptor utilized by both the viruses for respiratory cells entry.

- The median incubation time and the initial estimate of transmissibility rate are similar for both the viruses.

\section{Clinical Similarities}

The progression to severe disease follows the similar pattern in both the viruses:

- ARDS occur 8-20 days after onset of first symptoms and HRCT findings of lung disease show greatest severity by 10 days after initial onset of symptoms. ${ }^{22}$

- The poor prognostic factors in both the diseases are elderly and presence of cardiorespiratory and metabolic comorbidities. ${ }^{7,8,20}$

\section{Differences}

The key difference between the SARS-CoV-2 and the SARS outbreaks is the epidemic trajectory.

SARS epidemic: since its first description from China in 2002, SARSCoV affected 8098 cases with 774 deaths, and till it was successfully contained by interrupting all human to human transmission by July 2003 (in a matter of 8 months). A majority of reported cases were from five regions: China, Taiwan, Hong Kong, Singapore, and Canada. ${ }^{23}$

In contrast, COVID-19 has already caused 10 times as many cases as SARS in a quarter of the time trajectory and most countries of continents have reported cases of COVID-19.

Isolation and quarantine, social distancing, and communitycontainment measures (in the absence of vaccines ad specific treatment) are the recommended public health strategies to contain epidemics/pandemics. ${ }^{24}$

\section{How Successful Was These Measures DURING 2002-2003 SARS EPIDEMIC?}

\section{Isolation}

Isolation is defined as the separation of ill and affected people from noninfected people (in hospital settings or inhouse itself for mild infections).The key factors for a successful isolation are the following:

- Early care detection before the peak viral shedding occurs from an infected person.

- In case of SARS outbreak in the affected countries, most cases were identified and isolated within 4 days after onset of symptoms (peak viral shedding occurred in 6-11 days). ${ }^{25}$

- Working case definition: to suspect infected patients and early isolation.

Such measures resulted in drastic reduction in the secondary attack rates in households in Singapore and Canada. However, there were more cases of healthcare associated transmission. ${ }^{26}$
- Quarantine: 'Movement restriction of all close contacts of infected patients during the incubation period ideally combined with medical observation'. It can take place at home or in designated centers. The principle behind quarantining is that if the person under observation developed illness, he would not have any close contacts to spread the disease and effectively reducing the transmission of outbreak. If the contact developed symptoms, he/she would be investigated in a healthcare facility.

\section{Prompt and Comprehensive Contact Tracing is the Key to Success}

During SARS outbreak in 2002-2003, nearly 23,000 contacts were under quarantine in Toronto, Canada, ${ }^{27}$ and legally enforced quarantine measures were issued to contacts in Hong Kong and Singapore. ${ }^{26,28}$

Isolation and Quarantine are Effective in Stage I and Early Stage II of Epidemics or Pandemics

Beyond these, the next public health strategy is to apply community wide containment measures - an intervention that is applied to an entire community, city, or region to reduce personal interactions. It usually involves a large number of people than in isolation and quarantine. The measures include encourage personal and self-responsibility to identify disease, social distancing, cancelation of public gatherings, and community quarantine.

During SARS outbreak in 2002-2003, China implemented community quarantine closures of schools and public places, cancelation of public holiday, and Beijing lockdown in May $2003 .{ }^{29}$ Similarly, Singapore and Hong Kong had large-scale community measures to control SARS outbreak. ${ }^{30,31}$

All the affected countries also implemented strict hospitalbased measures to control spread of SARS. Isolation rooms with barrier nursing techniques, strict enforcement of PPE for staff, restriction of visitors, and movement of staff.

Above all these measures, following the WHO global alert and a stronger emergency travel advisory by the WHO on March 15, 2003, almost all countries initiated measures to rapidly contain the global transmission (entry and exit screening at all international airports and travel advisories to affected countries). ${ }^{32}$

\section{Will the Same Success Measures during SARS Work for SARS-CoV-2?}

The global community is facing a similar problem 17 years later but of different magnitudes. There are optimistic situations since the onset of outbreak favoring against the deadly agent.

- Most world countries have in place many capacity building initiatives especially under the WHO's International Health Regulations (2005).

- Sequencing of the viral genome within days of isolation by Chinese experts paving the way for design of diagnostics and therapeutics.

- Availability of diagnostic kits globally within 2 weeks of outbreak in China.

- Initiation of technical platforms for vaccine development and therapeutics by various global agencies. ${ }^{33}$

- Early clinical trials for therapeutically intervention were started in January $2020 .^{34}$

- A transparent and decisive action by Chinese politicians with a centrally coordinated response was initiated at the earliest. $^{35}$ 
However, the virus still seems to have an upper hand, visible by the staggering rise in number of cases globally every day. The plausible explanation for this observation could be the following:

- The early containment from Wuhan Province (the epicenter of the outbreak) could have been compromised due to various facilitating factors for person-to-person transmission-large population, dense living close to the source of infection, exhaustion of healthcare resources, and spring festival in China favoring traveling out of the infected population etc.

- COVID-19 has been shown to be transmitted even during the early phase of illness or asymptomatic period. Hence, isolation or quarantine measures may not be as effective as they were with SARS epidemic.

- The speed of transmission of SARS-CoV-2 may be higher than what is calculated as per the prevailing situation globally.

- Case fatality rate is reported to be $<10 \%$ which takes into account only the sicker cases. Most of the cases reported from China (81\%) were of mild disease which could result in infecting many more cases.

- Experience from China indicates that community spread is more prominent with SARS-COV-2 than with SARS. This is evident from the largest quarantine in history to date issued by China to prevent spread of infection.

Unfortunately, the exact reasons to explain these observations can be known only at the end of epidemic!

\section{What Needs to be Done?}

The Chinese should be appreciated for the strong political will in enacting some of the extreme measures in controlling the disease. Following up their experiences, containment of COVID19 by all countries and region should remain the focus. The economic costs of containment are really huge; however, the short-term losses will be far lower than the long-term losses due to non-containment!

This should be the priority for national, state, and local governments worldwide and the public health agencies to show the spread of virus. ${ }^{36}$

The long-term challenge is to prevent these outbreaks in future or improving our ability to respond to outbreak.

- We need to accelerate the work on therapeutics and vaccines for COVID-19. ${ }^{37}$

- Low- and middle-income countries should strengthen the primary healthcare systems: adequate infrastructure to fight epidemics, training of healthcare workers to monitor disease pattern, and early recognition of outbreaks. ${ }^{38}$

- All global governments should focus on robust disease surveillance with case database with regulation for information sharing as needed.

- To overcome obstacles for development of rapid, safe, and effective therapeutics and vaccines: technical, regulatory, and budgetary constraints.

- Global funding to be scaled up: government and other donors, Philanthropist foundations (such as, Bill and Melinda Gates Foundation), to fund for global public good.

- Strict regulations to ensure that care, therapeutics, and vaccines should be available, affordable, and reach for people who are at the center of outbreak and in greatest need rather than only the rich and wealthy. This just distribution would be the right strategy to contain transmission.
To conclude, the present COVID-19 outbreak is a lesson and warning to mankind of the ongoing and the yet to come challenge of emerging and reemerging infections!

Constant surveillance, prompt, early diagnosis and isolation, scientifically sound research to understand the transmission, and clinical dynamics and to develop countermeasures to contain the outbreak are needed on a war footing scale.

There is less time to waste if we need to save the next generation!

\section{References}

1. Habibzadeh $P$, Stoneman EK. The novel coronavirus: a bird's eye view. Int J Occup Environ Med 2020;11(2):65-71. DOI: 10.15171/ ijoem.2020.1921.

2. Ashour HM, Elkhatib WF, Rahman MM, Elshabrawy HA. Insights into the recent 2019 novel coronavirus (SARS-CoV-2) in light of past human coronavirus outbreaks. Pathogens 2020;9(3):186. DOI: 10.3390/ pathogens9030186.

3. Zhu N, Zhang D, Wang W, Li X, Yang B, Song J, et al. A novel coronavirus from patients with pneumonia in china, 2019. N Engl J Med 2020;82(8):727-733. DOI: 10.1056/NEJMoa2001017.

4. Benvenuto D, Giovanetti M, Ciccozzi A, Spoto S, Angeletti S, Ciccozzi $M$. The 2019-new coronavirus epidemic: evidence for virus evolution. J Med Virol 2020;92(4):455-459. DOI: 10.1002/jmv.25688.

5. Chan JF, Kok KH, Zhu Z, Chu H, To KK, Yuan S, et al. Genomic characterization of the 2019 novel human-pathogenic coronavirus isolated from a patient with atypical pneumonia after visiting Wuhan. Emerg Microbes Infect 2020;9(1):221-236. DOI: 10.1080/22221751.2020.1719902.

6. http://wjw.wuhan.gov.cn/front/web/showDetail/2020012009077. 2020.

7. Huang C, Wang Y, Li X, Ren L, Zhao J, Hu Y, et al. Clinical features of patients infected with 2019 novel coronavirus in Wuhan, china. Lancet 2020;395(10223):497-506. DOI: 10.1016/S0140-6736(20)30183-5.

8. Chen N, Zhou M, Dong X, Qu J, Gong F, Han Y, et al. Epidemiological and clinical characteristics of 99 cases of 2019 novel coronavirus pneumonia in Wuhan, china: a descriptive study. Lancet 2020;395(10223):507-513. DOI: 10.1016/S0140-6736(20)30211-7.

9. Chung M, Bernheim A, Mei X, Zhang N, Huang M, Zeng X, et al. CT imaging features of 2019 novel coronavirus (2019-nCoV). Radiology 2020;295(1):202-207. DOI: 10.1148/radiol.2020200230.

10. Chen L, Liu HG, Liu W, Liu J, Liu K, Shang J, et al. Analysis of clinical features of 29 patients with 2019 novel coronavirus pneumonia. Zhonghua Jiehe He Huxi Zazhi 2020;43:E005.

11. Wang D, Hu B, Hu C, Zhu F, Liu X, Zhang J, et al. Clinical characteristics of 138 hospitalized patients with 2019 novel coronavirus-infected pneumonia in Wuhan, China. J Am Med Assoc 2020;43:E005. DOl: 10.1001/jama.2020.1585.

12. Kui L, Fang YY, Deng Y, Liu W, Wang MF, Ma JP, et al. Clinical characteristics of novel coronavirus cases in tertiary hospitals in Hubei Province. Chin Med J (Engl) 2020;133(9):1025-1031. DOI: 10.1097/ CM9.0000000000000744

13. Chang Lin M, Wei L, Xie L, Zhu G, Dela Cruz CS, et al. Epidemiologic and clinical characteristics of novel coronavirus infections involving 13 patients outside Wuhan, China. J Am Med Assoc 2020;323(11):10921093. DOI: 10.1001/jama.2020.1623.

14. COVID-19 national incident room surveillance team. COVID-19. Australia: epidemiology report-2; 2020.

15. Wang XF, Yuan J, Zheng YJ, Chen J, Bao YM, Wang YR, et al. Clinical and epi-demiological characteristics of 34 children with 2019 novel coronavirus infection in Shenzhen. Zhonghua Er Ke Za Zhi 2020;58:E008.

16. Yang X, Yu Y, Xu J, Shu H, Xia J, Liu H, et al. Clinical course and outcomes of critically ill patients with SARS-CoV-2 pneumonia in Wuhan, China: a single-centered, retrospective, observational study. Lancet Respir Med 2020;8(5):475-481. DOI: 10.1016/S2213-2600(20)30079-5. 
17. Li Q, Guan X, Wu P, Wang X, Zhou L, Tong Y, et al. Early transmission dynamics in Wuhan, China, of novel coronavirus-infected pneumonia. N Engl J Med 2020;382(13):1199-1207. DOI: 10.1056/NEJMoa2001316.

18. Wrapp D, Wang N, Corbett KS, Goldsmith JA, Hsieh CL, Abiona O, et al. Cryo-EM structure of the 2019-nCoV spike in the prefusion conformation. Science 2020;367(6483):1260-1263. DOI: 10.1126/ science.abb2507.

19. China CDC weekly 2020;2:1-10.

20. Holshue ML, DeBolt C, Lindquist S, Lofy KH, Wiesman J, Bruce H, et al. First case of 2019 novel coronavirus in the United states. N Engl J Med 2020;382(10):929-936. DOI: 10.1056/NEJMoa2001191.

21. Zou L, Ruan F, Huang $M$, Liang L, Huang $H$, Hong Z, et al. SARS-CoV-2 viral load in upper respiratory specimens of infected patients. $\mathrm{N}$ Engl J Med 2020;382(12):1177-1179. DOI: 10.1056/NEJMc2001737.

22. Pan F, Ye T, Sun P, Gui S, Li L, Zheng D, et al. Time course of lung changes on chest $C T$ during recovery from 2019 novel coronavirus (COVID-19) pneumonia. Radiology 2020;295(3):715-721. DOI: 10.1148/ radiol.2020200370.

23. Wilder-Smith A, Chiew CJ, Lee VJ. Can we contain the COVID-19 outbreak with the same measures as for SARS? Lancet Infect Dis 2020;20:e102-e107. DOI: 10.1016/S1473-3099(20)30129-8.

24. Wilder-Smith A, Freedman DO. Isolation, quarantine, social distancing and community containment: pivotal role for old-style public health measures in the novel coronavirus (2019-nCoV) outbreak. J Travel Med 2020;272(2):taaa020. DOI: 10.1093/jtm/taaa020.

25. Cheng PK, Wong DA, Tong LK, Ip S-M, Lo ACT, Lau C-S, et al. Viral shedding patterns of coronavirus in patients with probable severe acute respiratory syndrome. Lancet 2004;363(9422):1699-1700. DOI: 10.1016/S0140-6736(04)16255-7.

26. Goh KT, Cutter J, Heng BH, Ma S, Koh BKW, KwokC, et al. Epidemiology and control of SARS in Singapore. Ann Acad Med Singapore 2006;35(5):301-316.

27. Svoboda T, Henry B, Shulman L, Kennedy E, Rea E, Ng W, et al. Public health measures to control the spread of the severe acute respiratory syndrome during the outbreak in Toronto. N Engl J Med 2004;350(23):2352-2361. DOI: 10.1056/NEJMoa032111.
28. Tsang T, Lam TH. SARS: public health measures in Hong Kong Respirology 2003;8(Suppl):S46-S48.

29. Ahmad A, Krumkamp R, Reintjes R. Controlling SARS: a review on china's response compared with other SARS-affected countries. Trop Med Int Health 2009;14(Suppl 1):36-45. DOI: 10.1111/j.13653156.2008.02146.x.

30. Leung GM, Quah S, Ho LM, Ho SY, Hedley AJ, Lee HP, et al. A tale of two cities: community psycho behavioral surveillance and related impact on outbreak control in Hong Kong and Singapore during the severe acute respiratory syndrome epidemic. Infect Control Hosp Epidemiol 2004;25:1033-1041. DOI: 10.1086/502340.

31. Leung GM, Hedley AJ, Ho LM, Chau P, Wong IOL, Thach TQ, et al. The epidemiology of severe acute respiratory syndrome in the 2003 Hong Kong epidemic: an analysis of all 1755 patients. Ann Intern Med 2004;141(9):662-673. DOI: 10.7326/0003-4819-141-9-20041102000006.

32. Wilder-Smith A. The severe acute respiratory syndrome: impact on travel and tourism. Travel Med Infect Dis 2006;4(2):53-60. DOI: 10.1016/j.tmaid.2005.04.004.

33. McCloskey B, Heymann DL. SARS to novel coronavirus_old lessons and new lessons. Epidemiol Infect 2020;148:e22. DOI: 10.1017/ S0950268820000254.

34. Wang C, Horby PW, Hayden FG, Gao GF. A novel coronavirus outbreak of global health concern. Lancet 2020;395(10223):470-473. DOI: 10.1016/S0140-6736(20)30185-9.

35. Nkengasong J. China's response to a novel coronavirus stands in stark contrast to the 2002 SARS outbreak response. Nat Med 2020;26(3):310-311. DOI: 10.1038/s41591-020-0771-1.

36. Gates B. Responding to COVID-19-A once-in-a-century pandemic? N Engl J Med 2020;382(18):1677-1679. DOI: 10.1056/NEJMp2003762.

37. Gates B. Innovation for pandemics. N Engl J Med 2018;378(22): 2057-2060. DOI: 10.1056/NEJMp1806283.

38. Frieden TR, Tappero JW, Dowell SF, Hien NT, Guillaume FD, Aceng JR. Safer countries through global health security. Lancet 2014;383(9919):764-766. DOI: 10.1016/S0140-6736(14) 60189-6. 